\title{
Close Look at the Accident in Fukushima Dai-ichi Nuclear Power Plant and What-if
}

\author{
Osaka University, Akira Yamaguchi
}

This study discusses about the possible preventive measures that could have been taken to minimize the damage and effect of the Fukushima Daiichi Nuclear Power Plant Accident. The reports by the Japanese government and Tokyo Electric Power Company were published in June 2011. It may be too early to ask "What if?" at this stage. However, extensive crisis management and external event planning are crucial for damage control; therefore this study aims to clarify and analyze the situation of the site.

\section{Introduction}

On June 2011, the governmental report on the accident of Fukushima Daiichi Nuclear Power Plant ${ }^{1)}$ and the report on the situation immediately after the disaster by the Tokyo Electric Power Company ${ }^{2}$ (TEPCO) were published. The governmental report first discusses the structure of nuclear safety regulations in Japan, the damage caused by the 2011 Off the Pacific Coast of Tohoku Earthquake and the tsunami it triggered, and the reason for the occurrence of the accident at the Fukushima Nuclear Power Plants. It is then followed by the responses to the nuclear emergency, release of radioactive materials to the environment, and effects on environment such as the state of radiation exposure. The report then discusses the Government's collaboration with the international societies, communication about the accident, future measures for resolving the accident, followed by the experiences from this accident. The report by Tokyo Electric Power Company summarizes the situations and facts based on the information and testimonies obtained from the relevant parties available during its publication.

These reports were drafted when the accident was still unresolved; therefore, analysis and estimation were conducted using the verified facts, and for what was not yet clear, using the most probable assumption. In addition, the reports contained comprehensive lists of problems and lessons learned from findings within and outside of Japan. The fact checking regarding the progress of the accident is still ongoing. Above all, the accident is not yet resolved. Are the lessons listed necessary and sufficient? Can they offer realistic solutions? The solutions listed in these reports must be validated in order to use them as safety measures. Atomic Energy Society of Japan also presents the experiences from the accident ${ }^{3)}$ and it shares many points with the other reports. Japanese and international societies must be continuously

DOI : 10.15669/fukushimainsights.Vol.1.106

() 2021 Atomic Energy Society of Japan. All rights reserved.

Originally published in Journal of the Atomic Energy Society of Japan (ISSN 1882-2606), Vol. 53, No. 9, p. 610-616 (2011)

in Japanese. (Japanese version accepted: July 12, 2011) 
provided with the information on the resolution of the accident, remediation of the accident site, and various activities for ensuring nuclear safety.

In the progress and the response in the accident, we must consider the origin of watershed, its occurrence, and if it was intrinsic. In this study, the events will be arranged in chronological order based on the abovementioned reports and the situation at the accident site will be assessed. To practically reflect the experiences from the accident, it is inevitable to ask: What if? We believe that this study will serve such a purpose.

\section{Nuclear Reactor and Fuel Pool: Report on the First 13 Days after the Accident}

Immediately after the accident, the Local Nuclear Emergency Response Headquarters may have been under extreme confusion while trying to respond to the accident. "On 2011 earthquake off the Pacific coast of Tohoku" was published by the National Headquarters for Emergency Disaster Control from the time immediately after the earthquake occurred until March 12, and jointly by the Headquarters for Emergency Disaster Control and the Nuclear Emergency Response Headquarters from March 13. TEPCO also published press releases. In the press release as of 5 am on March 12, the company admitted for the first time that a monitoring car detected a radioactive material, namely iodine, inside the premises of the power plant, with concentration higher than the normal value. Further, at one monitoring post, the concentration increased above the normal value and suggested that the water injection situation by isolation cooling system was unknown. Nuclear and Industrial Safety Agency (NISA) has published 196 reports on earthquake damage information on July 11. In June, the previously mentioned governmental and Tokyo Electric Power Company reports were published.

The accident at Fukushima Daiichi Nuclear Power Plant that became extremely difficult to control was a rare and special occurrence. There are many speculations and interpretations about this accident. The interpretations in the series of the commentary articles published so far in this journal are based on published information, which are deemed accurate. However, many uncertain elements and new facts are yet to be discussed; thus, these articles may be revised in the future. Therefore, the available facts must be analyzed, for which we follow the time series of events occurring at the Fukushima Daiichi Nuclear Power Plant.

\section{March 11: Occurrence of Earthquake and Tsunami}

On 14:46, March 11, every nuclear reactor (Unit 1-Unit 3) operating at the Fukushima Daiichi Nuclear Power Plant stopped automatically. Although external power supplies stopped, emergency diesel generator $(D / G)$ continued to run. On 15:27, the first tsunami hit and the D/G of Unit 1 stopped at 15:37, followed by those of Units 3 and 4 at 15:38 and those of Unit 2 at 15:41, respectively. The power could not be supplied because no off-site power was available, and station blackout ensued. Moreover, all the reactors lost decay heat removal function and were unable to transfer the decay heat to the final heat sink (seawater).

Furthermore, Unit 1 lost DC power batteries due to the tsunami and the batteries of Units 2 and 3 discharged after a few hours, making it impossible to check the plant parameter. Then, the reactor water levels and water injection conditions of Units 1 and 2 could not be verified, leading to the issuing of Article 15 report at 15:36 (failure of water injection to the emergency core cooling device). Thus, an extremely severe accident occurred where the water levels of 
reactors and the water injection conditions could not be verified and lighting/communication systems were lost, which literally forced the staff to cope with the situation blindly in the dark.

Verifying the status of the reactor cores of Units 1 and 2 was set to the highest priority. Batteries and cables were collected from companies in the premise; the schematics were confirmed and connections were developed. As the DC bus of Unit 3 escaped from the flood, its isolation cooling system and recorder could operate for a long time using the backup storage battery. Thus, for Units 3 and 4, to maintain the battery for the isolation cooling systems and the high-pressure coolant injection systems (HPCI system), which can operate without AC power source, measures to shut down unnecessary electric load were taken. Power sources were important.

TEPCO was attempting to secure power supply vehicles immediately after the tsunami. At that point, the early recovery of external power supplies was unlikely and because the emergency diesel generators (d/c) were submerged, there was no other options left but to secure the power supply vehicles. All the power panels of Units 1 and 3 were also submerged, which was not known at that point, suggesting that it was not possible to connect power supply vehicles even if they arrived quickly. The power panels (power center) of Unit 2 were partially usable, and cable installation was undertaken to connect power supply vehicles on priority. It must have been recognized at this point that the situation was quite severe, particularly for Unit 1 .

The isolation cooling system of Unit 2 was started manually at 15:39. However, the reactor water level could not be verified. At 17:12, the water injection method using the fire-extinguishing system and fire engines, which were the accident management measures, was examined. The diesel-driven fire pump (D/D FP) was started following this; however, it stopped soon afterward. At 21:02, the injection situation could not be verified and the local headquarters were concerned about fuel exposure.

The insolation cooling system of Unit 3 was started manually at 16:03, and its cooling was secured. Temporary lighting was installed in the main control rooms of Units 1 and 2 at 20:49 and that of Unit 3 at 21:58. Moreover, the liquid level of Unit 1 was $+200 \mathrm{~mm}$ from the top of the fuel (at 21:19) and then $+550 \mathrm{~mm}$ (at 22:00), whereas that of Unit 2 was 3,400 mm (at 21:50). Thus, the reactor water level was maintained and reactor cores were being cooled.

According to the analysis conducted later, the fuel of Unit 1 was uncovered to air by the evening of March 11 (2-3 h after the earthquake). After $1 \mathrm{~h}$, core damage started and the melted core was dropped into the lower plenum. This conclusion is based on the analysis with the following assumptions: (1) The isolation condenser (IC) did not operate after the station blackout due to the loss of AC power. (2) Leaking hole of 3-cm diameter appeared on the primary containment vessel (PCV) $18 \mathrm{~h}$ after the earthquake, which expanded to 7-cm diameter after $50 \mathrm{~h}$. This is an assumption for approximating the PCV pressure with the actual measurement to a certain extent. The time series of the extent of the opening of the IC valve after the station blackout is unknown; therefore, the contribution of IC to the cooling cannot be determined. The analysis result does not correlate with the measured water level.

At 21:51, radiation dose of the reactor building (R/B) Unit 1 increased and entry was prohibited. At 23:00, the dose inside the turbine building increased to $1.2 \mu \mathrm{Sv} / \mathrm{h}$ in a short duration. By this point, it must have been recognized the reactor core was damaged and the radioactive materials were released. Thus the situation must have been tense, and methods, such as venting or seawater injection, became realistic undoubtedly.

From the midnight of March 11 to the dawn of March 12, power supply vehicles arrived in sequence. In the building, about 40 people installed more than one ton of cable using a labor-intensive method in darkness for $>4-5 \mathrm{~h}$. This was done amidst scattered obstacles where 
repeated evacuations occurred every time a major tsunami warning was issued. Connection to the power panels was also extremely difficult. At this time, communication facility could not be used. Further, communication with the power plant response headquarters was difficult.

At this point, the damage of the reactor core was recognized. The power source could not be recovered quickly. Next, venting was attempted without using electricity. The drawing was collected in the evening to check the type/structure of the venting valve. Thus, it was judged that manual venting was possible. However, at 23:50, March 11, when the battery was connected to the pressure gauge of the drywell (D/W), the PCV pressure of Unit 1 reached 1.5 times the design value $(600 \mathrm{kPa})$. The PCV pressure was not been published possibly because it could not be measured due to power loss. Thus, performing PCV venting was crucial.

\section{March 12: Hydrogen Explosion in Unit 1}

By 0:06 on March 12, examination of the mass of radioactive materials that would be released when the pressure decreased from 800 to $100 \mathrm{kPa}$ performed along with the instruction for the venting preparation of Unit 1. At 0:30, evacuation of the residents within $3 \mathrm{~km}$ was verified and the second issuing for Unit 1 of Act 15 (abnormal increase of PCV pressure) was made at 0:49. Attention was focused on PCV venting. The PCV pressure was continuously measured until 05:14. By 02:30, it reached $840 \mathrm{kPa}$, which was twice the design value. The work at the reactor building $(\mathrm{R} / \mathrm{B})$, or suppression chamber where radiation dose was extremely high, continued in darkness using flashlights. Several difficulties were encountered, including prohibition on on-site operation at 04:30 due to the possibility of tsunami caused by the aftershock. Note that after 04:15, decreasing tendency of pressure was reported. The monitoring of the power plant premises on 04:23 reported approximately ten-fold increase of radiation dose near the main gate compared to that recorded 20 min earlier. In other words, it was verified that radioactive materials spread rapidly outside the building.

Amidst the fear of tsunami, operation of isolation cooling system of Unit 2 was verified on site at 02:55. This led to prioritizing of response to Unit 1 over Unit 2 that was being cooled. There is no record of operation of Unit 2 for some time after this point.

The cooling of the reactor core of Unit 1 remained insufficient. At 05:46, alternative water injection using fire-extinguishing pumps started. At 06:50, an order to conduct venting manually was given by the Minister of Economy, Trade, and Industry. The director of the power plant instructed to conduct venting in $2 \mathrm{~h}$ at 09:00. At 09:15, the electric valve was manually set to $25 \%$ opening. However, the opening operation of the pneumatic operation valve connected in series could not be conducted because the radiation dose was high. At 10:17, the venting valve was operated assuming that there was residual pressure in the compressed air system for instruments; however, its result was unknown. At 14:00, a temporary air compressor was installed to conduct venting. At 14:30, the PCV pressure decreased and the venting was deemed successful. However, the aforementioned analysis could not reproduce the time series of PCV pressure and there are still unclear aspects. Due to the depletion of the water source, injection of fresh water to the reactor core was terminated at 14:53. 80 tons of water had been injected until that point. Then, the instruction to continue the implementation of seawater injection was issued. In the afternoon on March 12, the success of venting of PCV and preparation of alternative water injection was in progress. There might have been a misconception in the Local Nuclear Emergency Response Headquarters that the significant crisis has been averted, even though the radioactive materials had already been released.

Hydrogen explosion occurred (15:36) when the injection preparation from boric acid solution injection system was completed following the electricity recovery by the power supply 
vehicles. The reactor building(R/B) of Unit 1 was severely damaged. The hoses prepared for the electricity facility of the boric acid solution injection system or for seawater injection were also damaged. In the end, seawater injection from the fire-extinguishing system line using fire engines began at 19:04. Regarding the release of radioactive materials, the reports by Japanese government state that its contents are merely references as there are uncertainties in the analysis conditions, the analysis model, and the progress of events.

The hydrogen explosion damaged the reactor building $(\mathrm{R} / \mathrm{B})$ and brought the preparation for the convergence of the accident done up to that point to nothing. Moreover, it scattered debris that contained radioactive material, severely worsening the access of the workers. If there was no hydrogen explosion, the subsequent progress after that point would have been significantly different. The failure to prevent the hydrogen explosion was the primary watershed.

Due to the hydrogen explosion of Unit 1, the emphasis shifted to Units 2 and 3. After the hydrogen explosion of Unit 1, the power plant director instructed to conduct venting of Unit 2 at 17:30. To prevent the hydrogen explosion of Unit 2, its early venting was urgent.

The isolation cooling system of Unit 3, which was in operation, tripped at 12:36. At 11:35, the high-pressure system started automatically due to the low water level of the reactor core. Instructions to prepare for the venting of PCV of Unit 3 were also given at 17:30 assuming that the situation of Unit 3 was less urgent as its reactor core was being cooled. Nevertheless, its hydrogen explosion had to be prevented, similar to Unit 2.

\section{March 13: Difficulty in Securing Nuclear Reactor Cooling}

The wet venting line setting from suppression chamber for Unit 2 was completed at $~ 11: 00$ on March 13. However, the PCV pressure was lower than the working pressure of the rupture disc; therefore, venting was not possible. The monitoring of pressure had to be continued under all circumstances. At 12:05, the power plant director instructed to use seawater for venting.

The high-pressure injection system of Unit 3 stopped at 02:42, two days after Units 1 and 2. As injection into nuclear reactor core using the isolation cooling system was not possible, at 05:10, the nuclear reactor cooling function was deemed lost and Article 15 report was issued. At 05:15, the power plant director instructed to set up venting line and the setting was completed at 08:41. At 09:08, rapid decompression of the nuclear reactor using safety relief valve was conducted. This triggered the increase of PCV pressure and enabled venting, and the decrease of pressure in the reactor pressure vessel (RPV) enabled injection of water into the reactor with smaller driving pressure. At 09:20, pressure decrease of the drywell was verified, indicating successful venting. The fresh water injection using the fire-extinguishing system line started at 09:25. However, the amount of water was insufficient and the water level in the nuclear reactor continued to drop. The director ordered to collect seawater from backflush valve pit ${ }^{1}$ and inject it to the reactor at 10:30. Aftershock was still continuing, prompting evacuation each time, and preventing the preparation from progressing. Meanwhile, fire prevention water tank did not contain any fresh water at 12:20. The seawater injection by fire engines from the fire-extinguishing system line started one hour later, at 13:12.

\footnotetext{
${ }^{1}$ A pit in which a valve for back flowing the seawater in the capillary is installed when washing the condenser capillary. It is located between the turbine building and water intake facilities.
} 


\section{March 14: Hydrogen Explosion also occurred at Unit 3}

In addition, Unit 3 did not contain sufficient seawater. To supply the backflush valve pit with seawater, the injection was stopped at 01:10. The seawater injection from the backflush valve pit through fire engines at last resumed at 03:20. From dawn, PCV pressure started to slowly increase and wet venting from the suppression chamber was conducted at 05:20. Venting and seawater injection were conducted; however, the injection was approximately $>10$ tons per hour, which was insufficient. The damage of the reactor core was presumably worsening. The decisive event in the form of hydrogen explosion occurred at 11:01. The reactor build$\operatorname{ing}(\mathrm{R} / \mathrm{B})$ and waste processing building were heavily damaged, where 11 people were injured and complete evacuation was ordered. The fire engines and hoses were damaged, debris with high radiation dose were scattered, and the backflush valve pit was no longer usable. The fire engines were moved to near the landing, and the line to send seawater to reactors Units 2 and 3 was re-established. Seawater injection resumed at 16:30.

Following the hydrogen explosion of Unit 3, the interest on site shifted to Unit 2. The hydrogen explosion of Unit 3 had significant effect on Unit 2. The venting valve was closed and could not be opened. Moreover, the fire engines and hoses prepared for seawater injection were no longer usable. Thus, at 13:25 on March 14, $70 \mathrm{~h}$ after the tsunami, the reactor water level of Unit 2 started to drop and the nuclear reactor cooling function was deemed lost (issuing of Article 15). The venting valve could not be used immediately, and decompression of the reactor pressure vessel (RPV) using the safety relief valve for seawater injection was attempted at $~ 16: 00$. The batteries were gathered from the vehicles in the premises. The decompression finally succeeded at $\sim 18: 00$. The exposure of fuel started at 17:17; at 18:22, the fuel was exposed. At 19:54, seawater injection finally started and cooling was resumed. Thus, the seawater injection to all the reactors started at last.

Some claim that the hydrogen explosion of Unit 2 was prevented because the blowout panel of Unit 2 opened when Unit 3 exploded, but it is not certain if that is correct. Moreover, no report mentions this. White smoke from the fifth floor of Unit 2 was seen in the following day at 08:25 on March 15. At 09:16, opening the external wall panels of the reactor buildings of reactors Units 5 and 6 was discussed. Among the conflicting information, it is possible that the Local Nuclear Emergency Response Headquarters was thinking that way. TEPCO opened three holes each on the roofs of the reactor buildings(R/B) of Units 5 and 6 on March 19 as a measure for the hydrogen release from the fuel pool.

After seawater injection to Unit 2, the attention was shifted to venting because hydrogen explosion could possibly occur at Unit 2 . Although the reason was unclear, the blowout panel of the reactor building (R/B) of Unit 2 was opened, leading to the release of hydrogen leaking in the building to avoid hydrogen explosion. Venting line setup was completed by 21:00. The pressure in the suppression chamber was lower than the working pressure of the rapture disc, even though the pressure of drywell was rising, which prevented wet venting. Thus, the method to conduct drywell venting was adapted at $\sim 23: 35$.

On the third day of the accident, reactors Units 1 and 3 had already experienced core meltdown and hydrogen explosion. The measures for Unit 2 were urgent in the severe situation, where its reactor core was completely uncovered and the pressure of PCV was increasing.

\section{March 15: PCV Breakage of Unit 2}

At Unit 2, venting was conducted at 00:02 on March 15, but the pressure of PCV did not decrease beyond $750 \mathrm{kPa}$. Though injection to the reactor continued, the pressure of PCV 
remained high. At 06:00, a large impact sound that was interpreted as hydrogen explosion occurred in the suppression chamber. At this point, the pressure of the suppression chamber turned to $0 \mathrm{MPa}$.

In the end, explosion occurred at each operating unit during the earthquake and an abnormal situation progressed where the total control of cooling was not possible at every nuclear reactor. Then, it was necessary to cool the reactors without interruption. By 07:00, 650 staff members were evacuated temporarily to Fukushima Daini Nuclear Power Plant, leaving 70 staff members that were required for monitoring and operation.

Unit 3 also seriously impacted Unit 4, which did not have fuel loaded in its nuclear reactor vessel. Damage near the fifth floor roof of the reactor building (R/B) of Unit 4 was discovered after the hydrogen explosion, and damage on the building itself was discovered at 08:11. Fire started in northwestern corner of the third floor of the same building at 09:38. It extinguished by itself at $\sim 11: 00$. The incidents in the building of Unit 4 may be partly due to the shortage of the staff in the building at the time, but the details are unknown.

At 23:05, extremely high dose of $4,548 \mu \mathrm{Sv} / \mathrm{h}$ was detected near the main gate.

On March 11, cooling of the fuel pool was insufficient at Units 1, 2, 3, and 4 immediately after the station blackout. However, the staff was forced to divert most of the resources to the response to the reactors, and securing the cooling of the fuel pools was postponed. The first instruction was the water injection order to the pool of Unit 4 given by the Minister of Economy, Trade, and Industry at 22:00 on March 15. This was after the hydrogen explosion at Unit 3 at 11:01 on March 14, the explosion near the suppression chamber of Unit 2 at 06:00 on March 15, and the severe damage on the reactor building of Unit 4.

Large quantity of radioactive material was released from March 15 to 16. Its quantitative analysis was published. The evaluation of Unit 1 was conducted under the aforementioned conditions. The evaluation condition of Unit 2 assumed that a $10-\mathrm{cm}$ diameter hole appeared on the drywell $21 \mathrm{~h}$ after the earthquake occurred and that a 10-cm diameter hole appeared on the suppression chamber immediately after the impact sound. Unit 3 was analyzed assuming that the reactor water level matches with the measurement and the water level inside the fuel area was not maintained. The released quantity of radioactive material is an estimation based on these assumptions.

\section{March 16: Cooling of Nuclear Reactor Fuel Pools Starts}

The seawater was injected to Units 1, 2, and 3 continuously, and the condition of the nuclear reactors was stable. The cooling progressed smoothly. Cooling of fuel pools started on March 16. The first measurement was taken for Unit 3. Water was sprayed from the helicopters of Japan Self-Defense Forces (JSDF) to the fuel pool of Unit 3. The cooling of the reactors was stable, and response to the fuel pools, which was the source of concern, started. As this was the first light of the convergence of the accident, it can be recognized as the second watershed.

As shown in Table 1, the heat generation by the fuel stored in the fuel pool is sufficiently low and the time until the upper ends of the fuel rods are exposed is 12 days (shortest in Unit 4). It is 278 days in Unit 1, and there is no need to apply almost anything. Thus, no problem is encountered without cooling for $\sim 10$ days. First, we believe that it was a reasonable choice to focus on reactors from Unit 1 to Unit 3. Although the exposure of the fuel in the pool of Unit 4 was pointed out from the beginning, there was a testimony that the surface of the pool water was visible in the pool of Unit 4 by visual inspection from the helicopter, therefore, the cooling of Unit 3 pool, of which the building and ceiling appeared severely damaged and through 
Table 1 Spare Days for Fuel Pool Cooling

\begin{tabular}{|l|r|r|r|r|r|r|c|}
\hline & Unit1 & Unit 2 & Unit3 & Unit 4 & Unit 5 & Unit 6 & Common Pool \\
\hline Fuel Assembly (Piece) & 292 & 587 & 514 & 1331 & 946 & 876 & 6300 \\
\hline Water in Pool (m3) & 1020 & 1425 & 1425 & 1425 & 1425 & 1497 & 3828 \\
\hline Decay Heat (Mcal/h) & 60 & 400 & 200 & 2000 & 700 & 600 & 1000 \\
\hline Heat Removal Water (kg/day) & 2500 & 16300 & 8200 & 81500 & 28500 & 24500 & 40800 \\
\hline Spare Day (day) ${ }^{* *}$ & 278 & 58 & 117 & 12 & 33 & 41 & 63 \\
\hline
\end{tabular}

* Water temperature is set at $50^{\circ} \mathrm{C}$

** Days required for the water level to be reduced to $4 \mathrm{~m}$.

which water can be discharged, must have been prioritized.

\section{March 17: Stable Cooling of Unit 3 Fuel Pool}

From March 17, freshwater and seawater were discharged on Unit 3 from water trucks and fire engines. Considerable cooling effect was secured, and discharging continued for some time. From March 29 and April 26, seawater discharging from mobile concrete pumps and freshwater injection using fuel pool coolant purification system, respectively, were conducted.

\section{March 20: Prospect of Cooling Fuel Pools Becomes Clear}

Seawater injection using fuel pool coolant purification system to Unit 2 started on March 20. Freshwater injection started on March 29. From March 20, freshwater was discharged on Unit 4 from water trucks and fire engines. From March 22 and March 30, seawater injection from mobile concrete pumps and freshwater injection were conducted, respectively. From March 31, freshwater injection using mobile concrete pumps to Unit 1 started.

The reason for the delay of response to Unit 1 was the sufficient margin for time it had for cooling, as shown in Table 1. The seawater injection to fuel pools of Units 1-4 was stable; thus, the prospect of fuel pool cooling was clear. As the cooling of both nuclear reactors and fuel pools became possible, the risk of further release of large quantity of radioactive materials was averted. Although there were still many problems, the emergency was avoided.

\section{March 23: Stable Cooling of Nuclear Reactors Established}

Seawater injection to the nuclear reactors from Unit 1 to Unit 3 continued. Figure 1 shows the temperatures of the reactor of Unit 1 and around the PCV. By the dawn of March 23, the temperature of the RPV shifted to $<400^{\circ} \mathrm{C}$. The nuclear reactor pressure decreased to gauge pressure $0.2 \mathrm{MPa}$ and remained almost constant. If the fuel was submerged in water, the water temperature had to be approximately $100^{\circ} \mathrm{C}$ at this pressure. If the measurement was correct, then the injected water evaporated and heated by the exposed fuel. At 02:33 on March 23 , external injection of seawater using the seawater system started in addition to the seawater injection from the fire-extinguishing system using fire pump. This increased the injection amount from 2 to 18 tons per hour. The temperature decreased in an instant, down to $\sim 200^{\circ} \mathrm{C}$. 


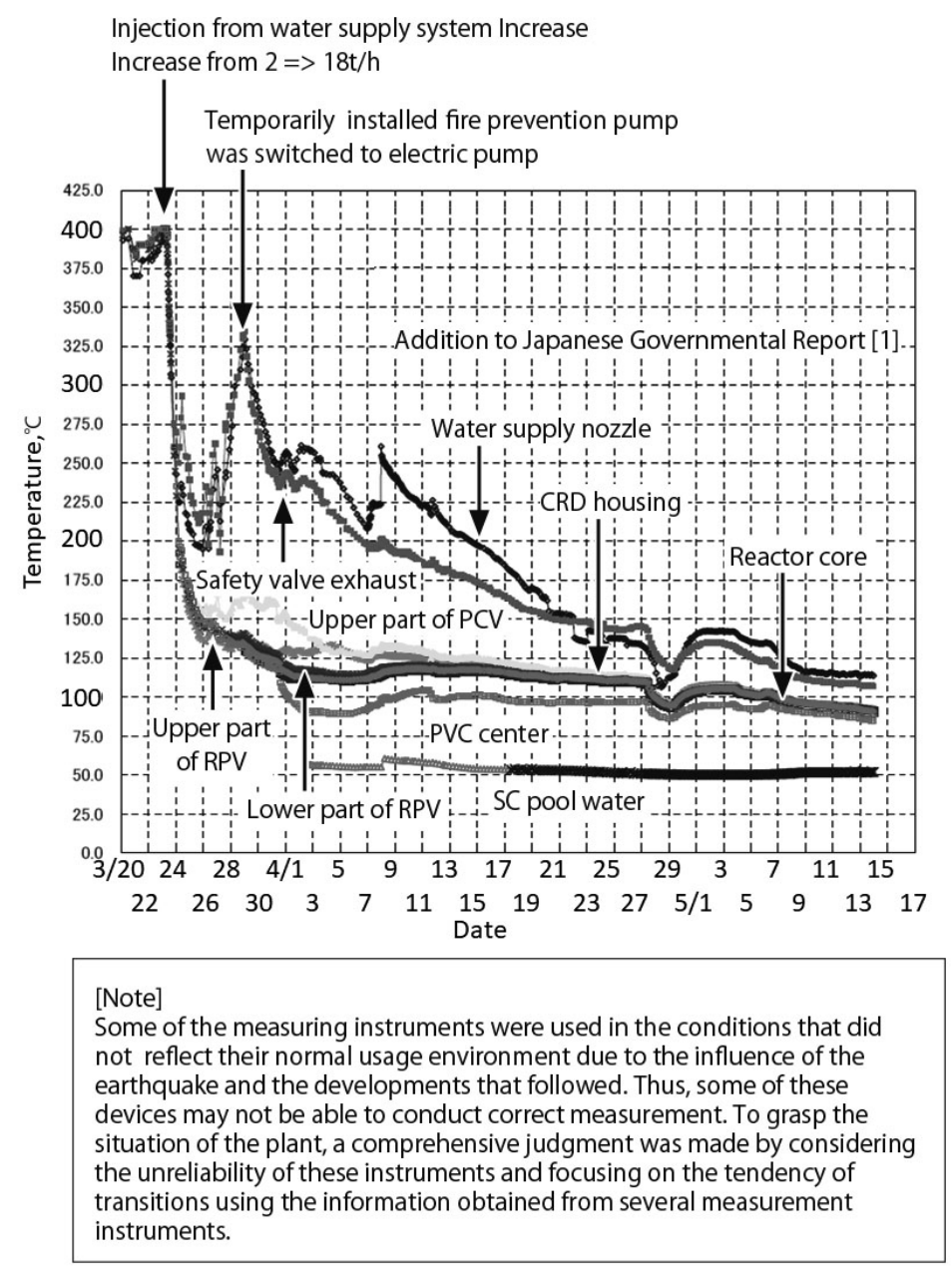

Figure 1 Temperature Transition of Nuclear Reactor of Unit 1 and Around PCV

At this stage, the staff on site may have recognized that all the nuclear reactors and fuel pools were stable. The responses after this point were steady and precise, and the situation gradually improved. Before the nuclear reactor temperature of Unit 1 decreased, the lighting of the central control room of Unit 3 recovered at 22:46 on March 22. Likewise, the lighting of the central control room of Unit 1 recovered at 11:30 on March 24. By March 26, the lighting of the central control room of Unit 2 recovered. On March 23, the third watershed occurred. From this point, main concern started to shift from cooling of nuclear reactors and fuel pools to the treatment of contaminated water.

\section{After March 24: Steps Toward Limiting Release of Radioactive Materials}

The cooling of nuclear reactors and fuel pools has been maintained since March 24. The water injection to nuclear reactors switched from seawater to freshwater for Units 1 and 3 on March 25 and for Unit 2 on March 26. Following this, the injection switched from seawater injection using the fire pump to freshwater injection using a temporary electric pump. In 
addition, transfer of the retained water under the turbine building started. On April 6, measures to prevent the high-level contaminated water leakage from the pit were taken. Nitrogen gas injection to Unit 1 started on April 7. The water of the fuel pool was analyzed, and most of fuel was judged to be in sound state. Moreover, hydrazine was injected to prevent oxidation.

The focus shifted to the secondary risk management, such as prevention of further hydrogen explosion or treatment of contaminated water. On April 17, the work schedule to the settlement of the accident was published by TEPCO. The most important task for the time being is the treatment of contaminated water. During this study, the system to decontaminate and circulate cooling water started its operation, allowing cooling without increasing contaminated water.

\section{Problems Pertaining to Disaster Prevention (INES Evaluation and SPEEDI)}

Several problems are encountered with respect to protection against radiation, evacuation of the residents, and providing accurate information. Nuclear and Industrial Safety Agency (NISA) has the responsibility of conducting an International Nuclear Event Scale (INES) evaluation. On March 11, they published that Units 1 and 2 were deemed impossible to cool, prompting issuing of INES level 3. On March 12, level 4 was issued in response to the venting of Unit 1 and the hydrogen explosion at the reactor building(R/B). On March 18, recognizing core damage at Units 2 and 3, the level was raised to 5 and level 3 was issued for the fuel pool of Unit 4 in response to its loss of water supply and cooling function. Thus, the accident was interpreted as the same level as the Three Mile Island Accident.

About a month later, on April 12, INES evaluation was raised to level $7^{4)}$. This was based on the analysis that the total released amount of radioactive materials from the nuclear reactors to atmosphere was $370,000 \mathrm{TBq}$ in iodine conversion. This was also judged to match with the result of the reverse calculation from the monitoring measurement result. The standard for level 7 is $50,000 \mathrm{TBq}$ in iodine 131 conversion, which the measurement exceeded. Thus, international community deemed this accident to be of the same level as the Chernobyl Accident. The reason for concluding that the released radioactive materials reached the standard of INES level 7 was the analysis based on aforementioned assumptions. However, the release from fuel pools and the release into the ocean were not evaluated. Meanwhile, the nuclear reactors are being stabilized and the release of radioactive materials is on decreasing trend.

In the introductory part of INES manual by the International Atomic Energy Agency ${ }^{5}$, it is stated that "INES standard must be used promptly and consistently to communicate the safety meaning of the event to the public from the view point of radioactive source." It then defines INES as a communication tool between specialists, the media, and the public. Thus, to avoid confusion among the media and the public on understanding the event, it is important to promptly issue INES Accident scale.

On the occasion of the Fukushima Daiichi Nuclear Power Plant Accident, evacuation orders were issued as follows.

On March 11, the evacuation area was $3 \mathrm{~km}$ and the sheltering area was $3-10 \mathrm{~km}$. On March 12, the evacuation area was $10 \mathrm{~km}$ and on the same day it was changed to $20 \mathrm{~km}$. Moreover, the sheltering area was set to $20-30 \mathrm{~km}$ on March 15. Thus, when the level was raised to 5 on March 18, the evacuation of the local residents was already complete. 
The issuing of INES level at the early stage could be considered prompt and appropriate in the light of the resident evacuation. In addition, the fact that it was raised at the point of March 18 was an effective message to communicate the seriousness of the radioactive materials release on March 15 and 16, even though the evacuation was already complete.

If INES is a communication tool, then it should utilize System for Prediction of Environmental Emergency Dose Information (SPEEDI). If the weather condition and the information of how the radioactive materials are spreading were published at the point of venting on March 12 and if each municipality (cities, towns, and villages) obtained those information quickly, understood them, and utilized them for disaster prevention measures in conjunction with the INES information, it must have greatly contributed to the protection against radiation.

We believe that the reevaluation to level 7 on April 12 was premature because there was no further release of radioactive materials. The INES manual states that the standard number of 50,000 TBq for level 7 itself is meaningless. Prompt evaluation should be made with a premise that INES scale is a standard for discussing the significance of accidents from the perspective of disaster prevention. In contrast, the evaluation of the safety engineering implications of an accident could be made after adequate analysis. As a consequence, INES scale may have triggered reputational damage. INES scale can be officially evaluated after the cause was determined and preventive measures against recurrence were established. It is possible to consider that following problems were revealed; consideration by specialists must be conducted from the viewpoint of radiation safety of the public, whether the INES level classification were appropriate for a severe accident, how it should be applied to an accident with multiple core damage, and how to consider the difference in release forms and compositions depending on the accident types (e.g., the power excursion type and the heat removal loss type).

\section{Learning from the Previous Lessons}

A method, known as Accident Sequence Precursor (ASP) Analysis, studies the precursor events for the previous serious accidents and analyzes what type of sequence would unfold if they lead to core damage. The U.S. Nuclear Regulatory Commission (USNRC) has been implementing the ASP program since 1979, providing important discussions and knowledge on the meaning of the abnormality and accidents that actually occurred for nuclear safety to the American Nuclear Industry. In conjunction with the development of probabilistic risk assessment (PRA), the ASP program matured. ASP and PRA are like the two wheels of a cart for learning lessons.

The first PRA study in the US was Reactor Safety Study (WASH-1400) conducted in 1975. To conduct crosscheck evaluation of WASH-1400, Lewis commission was established by USNRC. One of the many suggestions included in the 1978 report was to utilize operation data to the risk evaluation of nuclear power plants. It pointed out that when a potentially important accident sequence and its precursor events occur, they should be analyzed via comparison with the scenarios examined in PRA. Following this suggestion, the risk analysis department of USNRC started ASP in the summer of 1979. Coincidently, it was immediately after the Three Mile Island Accident. The first ASP report ${ }^{6}$ ) was published in 1982. The important point was the evaluations unique to plants. USNRC started to develop PRA models tailored for individual plants. 
Following is an example of external power supplies loss due to flooding ${ }^{7)}$. La Blayais power plant in France has 900 MWe PWR and located in the marshes near the mouth of the Gironde estuary northwest of Bordeaux. Extrapolating the records of flood water level from last few decades, its designed flood water level was set at $5.02 \mathrm{~m}$. At the time of the flood of December 27, 1999, Units 1, 2, and 4 were operating in rated power output and Unit 3 just had its fuel changed. The combination of strong wind and high tide caused the flood to far exceed the designed flood water level, and the external power supplies of Units 2 and 4 were lost between 19:30 and 22:20, and the nuclear reactors stopped. The flood started from 19:30, and the high tide occurred at 21:30. The water flooded from the northwest of the premises and caused severe damages to Units 1 and 2. The electricity room, the seawater pump room, and fuel building were flooded, as well as the decay heat removal function, the auxiliary machine cooling system, and the electricity system were lost.

For nuclear safety analyze precursor events and critical events (which could potentially be disaster) occurring in each country firmly must be analyzed to extract lessons and to consider what would happen if such events occurred in plants in Japan and evaluate it, having an attitude that proactively strengthen vulnerability if there is any chance of it.

\section{Conclusions}

The Local Nuclear Emergency Response Headquarters were doing considerable work in extreme conditions such as the measurement instruments failure and the loss of lighting/communication function due to the station blackout and the bad access due to the high radiation dose. The station blackout and the loss of heat sink could be considered inevitable after that tsunami. Examining the background of the accident, if there was a possibility for taking different measures, it was only in between the venting preparation instruction at 00:06 on March 12, and the successful venting at 14:30. As it was clear at the point of 02:55 that Units 2 and 3 were being cooled, all the resources could have been used for Unit 1. During this time, PCV venting and alternative water injection were attempted with no avail. Venting succeeded only at 14:00. Then, hydrogen explosion occurred at 15:36. We believe that this was the first watershed. If venting was conducted before hydrogen leaked to the reactor building (R\B), the explosion would not have occurred and many more measures could have been taken.

In the end, the response was always late until March 15. The nuclear reactors of Units 1, 2, and 3, and the fuel pools of Unit 1 to 4 were heavily damaged. In contrast, the cooling of the reactors with seawater injection using fire pump was established by March 16. The cooling of fuel pools also started. This was the second watershed. Following this, stable cooling of the fuel pools was possible by March 20. The final watershed was on March 23. With the nuclear reactor temperature still being high, further release of radioactive material was possible. Sufficient cooling was secured by increasing the amount of water injection from the water supply system. The reactor temperature dropped immediately. The desperate situation during the 13 days after the tsunami finally improved. Conducting What if analysis of what would have happened if different measures were taken is possible, but the situation at the accident site was extremely difficult.

The possible watershed of the development of this accident were March 12 (deterioration after the hydrogen explosions), March 16 (maintaining reactor core cooling) and March 23 (stable cooling of reactor cores and pools). If venting was conducted promptly at Unit 1 and the hydrogen explosion was prevented, it would not have reached this situation. However, it 
is not clear whether that would have been possible when there were no electricity, lighting or communication, debris were scattered and aftershock or tsunami warnings were constantly issued. One could only say that the force of tsunami is incredible.

There was severe release of radioactive materials in this accident. We believe that for the appropriate and prompt evacuation of the local residents, utilization of INES Accident scale and SPEEDI is essential. However, INES Accident scale did not necessarily effectively function. Japan is expected to provide remedial measures for such issues. Moreover, information, such as SPEEDI, was not fully utilized and maintaining the cooperative system between the national government, private businesses, and local municipality was not possible. Effective policies must be discussed.

If we search among the international experiences of operation, similar critical experiences (which could potentially be disaster) will certainly be found. It is important to remember the importance of learning from experiences, and a system to reflect them on the safety improvement should be constructed. No matter how many safety measures we take, scenarios that go beyond our imagination will continue to occur. However, they will appear firstly as precursor events and critical events (which could potentially be disaster). Problems that appeared this way should be properly analyzed while they are still in their early stages, run these scenarios at each plant to find out their individual vulnerabilities, and conduct risk management. Such steady efforts are important and is a realistic and effective approach.

\section{References}

1) The Government Nuclear Emergency Response Headquarters. Japanese Government Report on Nuclear Safety for IAEA Board Meeting, On the Accident at Fukushima Daiichi Nuclear Power Station of Tokyo Electric Power Company. 2011 June. [in Japanese]

2) Tokyo Electric Power Company. On the Response Situation Immediately after the Disaster at Fukushima Daiichi Nuclear Power Station. [in Japanese]

3) Atomic Energy Society of Japan. http://www.aesj.or.jp/information/fnpp 201103/chousasenmoniinkai. html

4) Ministry of Economy. Trade and Industry press release. On the Application of INES (International scale for evaluating international nuclear power/radiation phenomena). 2011 April. [in Japanese]

5) INES. The International Nuclear and Radiological Event Scale User's Manual 2008 Edition.

6) Precursors to Potential Severe Core Damage Accidents : 1969_1979. A Status Repor (NUREG/CR2497, Volume 1). 1982 June;

7) Gorbatchev A, et al. Report on flooding of Le Blayais power plant on 27 December 1999. 